\title{
La violencia en la enseñanza media
}

Lía Cosse, Ana Salveraglio, Zulma Uraga

"Tratemos en cambio de educar a los muchachos con una mayor ambición. ¡Para que se conviertan en soberanos!

¿Qué importa ser médico o ingeniero!"

Estudiantes de Barbiana (1971)

\section{PRESENTACIÓN DEL PROBLEMA dE LA INVESTIGACIÓN}

El presente trabajo de investigación se refiere a como se manifiesta la violencia en los adolescentes y jóvenes que asisten a los centros educativos de ciclo básico dentro de la enseñanza pública, con la finalidad de comprender las motivaciones de su comportamiento.

Nuestra preocupación nace directamente ligada a la práctica educativa cotidiana. Es en ella que estamos inmersas, aún cuando ejercemos la docencia a diferentes niveles y de esa experiencia parte nuestro propósito de investigar sobre las motivaciones de conductas que han acentuado su perfil, más cargados de violencia en los últimos años.

Desarrollamos el paradigma de la complejidad para sustentar el aporte de las diversas disciplinas, (didáctica, psicología social y psic oanalítica, estructuralismo, interaccionismo simbólico) que ayudan. a la comprensión de los hechos, en el esfuerzo de no banalizar el comportamiento de los estudiantes en la institución educativa, evitando caer en simplificaciones interpretativas a la hora de las conclusiones.

No pretendemos suscribir opiniones optando por alguna de las distintas corrientes de pensamiento en que nos apoyamos, sino tomar de cada una el mayor aporte posible para la comprensión del problema que nos preocupa.

El punto de partida en cuanto al marco teórico, es nuestra ubicación como docentes y educadores frente a los jóvenes. Es decir desde la perspectiva del adulto frente al ser inmaduro, en proceso de formación, pero propietario de una potencialidad siempre inesperada como tiene el adolescente. Partimos del supuesto tal vez obvio, pero a veces olvidado en nuestro medio que no se puede educar sin entender, (Cardoso- Correa, 1996)․․․ Observar la forma en que interactúan los alumnos entre sí y con los adultos en un liceo, constituye una realidad compleja, tan compleja como la vida misma. Nos apoyamos en este sentido en el trabajo de Marta Souto (1996). Dice la autora acerca del conocimiento didáctico, que nosotros llamamos perspectiva del educador: "Es un conocimiento complejo de una realidad compleja (...). Dificultad, donde nuestra mente queda perpleja, donde el pensamiento causal, lineal, resulta insuficiente para entender las incongruencias que se presentan (...) heterogeneidad, contradicciones, paradojas, conflictos que para conservar su sentido no pueden ser reducidos, sino que requieren explicaciones dialógicas que respeten su carácter heterogéneo y analicen su complementariedad. Fenómenos aleatorios, incertidumbre. Donde aparece lo imprevisible (...). Donde el desorden tiene lugar al igual que el orden (...). Donde el principio de la incertidumbre es incluido $»^{2}$ (Marta Souto, 122). La referencia al concepto de incertidumbre nos pareció significativa aún en su reiteración porque la falta de certezas y seguridades es una característica del mundo de hoy, que no reconoce límites etarios o de género.

«¿Qué pasa en las clases y en la escuela con el tiempo? ¿Hay un tiempo propio de lo escolar? ¿Hay una desconexión con el afuera, una descontextualización, una separación de los tiempos externos, vitales?

¿Se reedita un tiempo eterno?

¿Es un indicador de enajenación, de cosificación, de burocratización de la enseñanza?» (Souto, 1996,147) 
"Dentro de la escuela y de las clases existe un tiempo propio. Podríamos hablar provisionalmente de una atemporalidad, en tanto:

- el tiempo real, social, el de los sucesos de la vida externa a la escuela no está presente dentro de ella;

- el tiempo personal, vivido por cada uno de los actores no tiene cabida;

- el tiempo compartido (...) parece no suceder (...) . Se vive un eterno presente. (...)»

(Souto, 1996, 145)

\section{OBjetivo GenERAL dE LA INVESTIGACIÓN}

Elaborar un conjunto de sugerencias prácticas, de carácter transformador acerca del tejido de interrelaciones humanas entre alumnos y los demás actores-sectores de un establecimiento educativo (liceo de Ciclo Básico).

Describir las interacciones violentas entre estudiantes, estudiantes y docentes indirectos, estudiantes y docentes directos.

\section{Metodolocía}

Abordamos el trabajo desde la perspectiva fenomonológica que trata de entender los hechos desde el punto de vista del actor.

De acuerdo con Taylor y Bogdan «El fenomenólogo busca comprensión por medio de métodos cualitativos, tales como la observación participante, la entrevista en profundidad y otros que generan datos descriptivos (...)».3

Para nuestro trabajo interesa tanto la opinión de un «mal alumno», como la de un estudiante b rillante, la de todos y cada uno de los adultos vinculados a la función educativa. La selección de actores entrevistados se realizó de acuerdo a su vinculación con el tema, además de la insoslayable necesidad de acotar el trabajo.

Comprender e interpretar el entramado de relaciones humanas en el tiempo libre del liceo, exige instrumentos propios de la metodología cualitativa.

La investigación se ha realizado en tres centros situados en diferentes zonas de la ciudad donde ha trabajado cada una de las integrantes del equipo, realizando la colecta de datos.

Para realizar la colecta de datos cada una de las integrantes del equipo de investigación realizó quince observaciones directas en el tiempo libre de los estudiantes o sea durante los recreos y horas libres debidas a la falta de profesor. Los espacios observados fueron patio, cantina, corredores y escaleras. Se observaron todos los posibles cruzamientos espacio-tiempo en un turno completo de tiempo extendido. De acuerdo a nuestra conceptualización de violencia observamos según las siguientes pautas: violencia verbal, gritos, insultos, apodos ofensivos, amenazas; violencia física: empujones, zancadillas, arañazos, golpes, mordiscones, tirones de pelo y de ropa, peleas, agresiones al entorno. Se realizó una anotación inmediata de lo observado en forma cronológica en un cuaderno de observaciones.

Respecto a las entrevistas se elaboraron pautas para facilitar el estudio comparativo en forma vertical y horizontal de los tres liceos estudiados. Se entrevistaron los siguientes docentes en cada uno de los institutos: director, profesores adscriptos, docentes directos e integrantes del equipo interdisciplinario en los liceos que lo tenían.

\section{RESULTADOS}

El análisis de las entrevistas así como el de los numerosos incid entes claves registrados en las observaciones, nos permitieron llegar a los siguientes resultados:

Los adultos entrevistados tienen una percepción clara de los problemas que se viven en el liceo acerca de la violencia, sus formas de manifestarse y sus posibles causas. No así los jóvenes que tienen una confusión respecto de como los adultos conciben la violencia y su propia visión del problema. 
Los distintos niveles de exigencia - permisividad debido a la heterogeneidad docente y a la falta de un enfoque común de la problemática adolescente, lleva a la confusión del alumnado provocando distorsiones en su conducta.

El exceso de horas libres lleva al aburrimiento de los jóvenes que no saben que hacer y comienzan a empujarse, correrse, hacerse zancadillas, golpearse unos a otros provocando llantos y hechos violentos que generan observaciones y suspensiones por parte de la Institución.

Muchos problemas de violencia que se dan en el liceo tienen su origen en conflictos y rivalidades del barrio. Estas situaciones invaden el ámbito liceal a través de los comentarios que van y vienen entre los propios alumnos, distorsionando y agravando los hechos que originan el conflicto.

Observamos una fuerte desaprensión de los estudiantes hacia el entorno físico y los objetos materiales que deben cuidar porque les pertenece a ellos y sus compañeros de otros turnos y de muchas generaciones

El exceso de alumnos contrasta con la falta de personal y es causa de gran parte de la problemática que hemos descripto.

El liceo es visto por los estudiantes como obsoleto y vetusto y los mensajes de los profesores son considerados banales, carentes de interés y por tanto no pueden competir con los de los medios masivos de comunicación.

La inadecuación de los locales genera un ámbito material violento, por su deterioro, falta de luz, limpieza. «La mugre tradicional», expresión de uno de nuestros entrevistados, transmite vivamente la situación locativa. Es dable destacar que de los tres liceos estudiados, dos de ellos son casas que se «adaptaron», uno de ellos era una mercería y otro una casa de atención psiquiátrica.

Conclusiones

Existen dificultades de comunicación entre adolescentes y docentes en general debido al manejo de códigos diferentes relacionados con la cultura de que son portadores. Pensamos que es altamente relevante que los adultos que tienen responsabilidades docentes y no docentes deben tratar de superar las dificultades de comunicación y contextualizar las expresiones verbales de los estudiantes, en relación a la cultura de la que son portadores. Esto evitaría enfrentamientos que se dan con demasiada frecuencia.

El liceo como institución se debate entre la necesidad de cumplir con el rol propio de la educación formal y una nueva tarea en relación a la socialización primaria que la familia no cumple. Esto explica la falta de límites de los jóvenes y su dificultad para entender la normativa liceal.

Los alumnos en su comportamiento cotidiano, cuando transgreden la normativa liceal, demuestran la necesidad de llamar la atención, de ser protagonistas y de ser escuchados. Cuando han tenido oportunidad de participar en actividades colectivas de su interés, demuestran que saben responder a la confianza que se ha depositado en ellos.

Los jóvenes perciben los criterios y normas de los educadores como excesivamente represivos: «todo es no», es la breve pero reveladora expresión de un estudiante. Por este motivo muchas veces actúan por reacción, con un comportamiento violento.

Los factores que influyen en el contexto en que se manifiesta la violencia constituyen una causalidad compleja y actúan muchas veces potenciando el problema objeto de esta investigación.

Una conceptualización de relevancia tiene que ver con la estrecha relación que existe entre los problemas que observamos en la institución educativa, en cuanto a las manifestaciones de violencia, y su relación con el contexto socioeconómico y cultural de los estudiantes. 


\section{PROPUESTA}

En base a estas conclusiones y de acuerdo con nuestro objetivo general de elaborar un conjuntos de sugerencias de carácter transformador proponemos las siguientes alternativas:

- La existencia en el liceo de un equipo multidisciplinario para el abordaje de una problemática tan compleja como la del adolescente.

- Más docentes indirectos para una atención personalizada del alumnado.

- Trabajar en el tema valores para orientar a los jóvenes que reciben mensajes contradictorios de los adultos y de los medios masivos de comunicación.

- El trabajo en equipo para dar soluciones prácticas y viables dentro de cada Institución.

- Creatividad en la búsqueda de alternativas para el uso del tiempo libre por parte de los estudiantes.

- Necesidad de contextualizar los contenidos programáticos de acuerdo con el interés de los educandos así como modificar las metodologías y evaluaciones utilizadas en el aula.

${ }^{1}$ Cardozo Cuenca, R. y Correa, L. (1996) «Cuando la Educación hace síntoma». Buenos Aires, Roca Viva.

2 Souto, M. y otros (1996) «Corrientes didácticas contemporáneas». Buenos Aires, Paidós.

${ }^{3}$ Taylor, S.J . - Bogdan, R. 1987 «Introducción a los métodos cualitativos de investigación». Buenos Aires. Paidós. Pág. 16. 